\title{
Open Science - the new paradigm for research and education?
}

\author{
Sabine Kunst ${ }^{\mathrm{a}}$ and Andreas Degkwitz ${ }^{\mathrm{b}, * \dagger}$ \\ ${ }^{a}$ Humboldt-University Berlin, President, Unter den Linden 6,10099 Berlin, Germany \\ E-mail: praesidentin@hu-berlin.de \\ ${ }^{\mathrm{b}}$ Humboldt-University, Chief Librarian, Unter den Linden 6, 10099 Berlin, Germany \\ E-mail: andreas.degkwitz@ub.hu-berlin.de
}

In the context of the digital transformation, open science became one of the leading topics of national and international science policies. With regard to the EU we can see this in projects such as the "European Open Science Policy Platform" (OSPP) ${ }^{1}$, the "Open Science Monitor", the "European Open Science Cloud" (EOSC) $)^{2}$ and several other activities. A key element of open science is to claim for openness of digital research and teaching. This means that research results, research data, research methods and procedures as well as course and teaching content, software and tools are available free of charge and can be reused.

The purpose of open science is to improve disciplinary and interdisciplinary cooperation as well as low-threshold forms of knowledge and technology transfer including citizen science. Open science does not only concern changes in research and teaching processes. It also includes funding, governance, collaboration and standardization processes. These issues will be crucial points for preparing the Berlin University Alliance.

Open science is without doubt closely related to the digital transformation of science and the research infrastructures. These new shapes will enable new forms of research and collaboration as well as new options to distribute text publications, databases, multimedia objects etc. In the context of digitalisation the term of openness has an extended meaning as the paradigm of open access demonstrate. Open access is the scientific version of self-publishing and includes quality management procedures regularly such as peer reviewing in particular. Open access authors publish their research results by themselves supported by the infrastructures of libraries and/or publishers. The existing technology makes it possible for researchers to manage the publication process independent of publishers. They are able to shape it to their own discretion.

\footnotetext{
${ }^{*}$ Corresponding author. E-mail: andreas.degkwitz@ub.hu-berlin.de.

†This paper is a shorted version of the following article: Degkwitz, Andreas: "Open Science" - Treiber des digitalen Wandels in Bibliotheken. - in: "die hochschule" 2/2017. - S. 20 - 29.

${ }_{1}$ https://ec.europa.eu/research/openscience/index.cfm?pg=open-science-policy-platform

${ }^{2}$ https://ec.europa.eu/research/openscience/index.cfm?pg=open-science-cloud
} 
To avoid any details I would like to point out two issues that are essential to understand the extended meaning of openness. The first issue is the availability of the publications, the second issue concerns the financial aspects and related effects.

Open Access publications must be (1) discoverable, (2) readable and/or usable and (3) sustainably available. In order to meet these standard requirements for scientific publications, Open Access publications have metadata entries according to common metadata standards. The publications have to be edited as PDF, as HTML or by other standard formats and stored on repositories of libraries and/or publishers. These standards guarantee the free accessibility based on creative commons licenses ${ }^{3}$ as well as the sustainable availability.

The second issue of open access publication is the new funding model. Funding is no longer "readerbased or usage-based" on subscriptions, but "publication-based" by article processing charges (APCs). In future times this will lead to a change of responsibilities. Libraries will continue to support for publishing by APCs and monitor the development of open access publishing. However to fund the APC-based publishing might be handed over to the authors. Against this background the libraries wouldn't be longer in charge of the publication budgets. These change might be the starting point of a new eco-system of scientific publishing and - at the same time - of literature and information provisioning as well as future cooperation between authors and infrastructures. The new roles and tasks could look as follows:

- The traditional publishers focus on organizational and technical services of the publication process. Their brands will continue to play an important role.

- New Open Access publishers enter the competition for customers and market shares. They will try to gain influence by price of article fees, by openness of the open peer reviewing process or by the performance of their publications.

- Additionally initiatives of open access publishing are coming up by disciplines or by universities as well as by academic libraries. These initiatives seem at the forefront of experimenting with new forms of publications based on digital or virtual working and research environments.

The brief overview about the development of open access makes clear, that these developments are going on a high dynamic level. In context with the economic impact, which can not be finally analyzed yet, a new eco-system is emerging, which is heavily influenced by collaborative or shared-economy approaches. The previously linear value chain is moving more and more to a network of players, who are involved in scholarly communication anyway. To store publications is not the end of the publication process anymore. Moreover the openness of the publications enables contextualization and linkage of published material by completely new ways.

What has been said about open access, is also true for open data. The extended significance of openness relies on the fact, that research data are much more part of the research process than open access publications. Which requirements and expectations are associated with open data and research data management?

Two reasons for open data are the traceability of research results and the reuse of research data for new research projects. The prerequisites for this are findability, accessibility and interoperability, which are combined in the so-called FAIR principles ( = Findable, Accessible, Interoperable, Reusable) ${ }^{4}$. As we have observed for open access publications standards are fundamental for the reusability of research data. Otherwise it is not possible to fulfill and to guarantee the FAIR principles.

\footnotetext{
${ }^{3}$ https://creativecommons.org/faq/

${ }^{4}$ http://www.forschungsdaten.org/index.php/FAIR_data_principles
} 
One key element for the traceability of research results and the reusability of research data is the availability of appropriate software. Therefore data must be generated and processed using software that meets the requirements of open too. Under the heading of open source software components including documentation are available on $\mathrm{GitHub}^{5}$ in order to be able to use and process Open Data as well as open available data publications on the software side.

Open Access and Open Data show that "Open Science" is entering a new "Eco-System". As a result the existing governance structures will be substituted by new participation and decision-making structures in the sense of a collaborative or sharing economy. Against this backdrop the study "Knowledge Exchange Approach to Open Scholarship" ${ }^{6}$ questions the following topics concerning funding, governance and organization of open science:

- Evaluation and impact (economy) of academic goods from the perspectives of the society and the politics, the disciplines and the individual researcher;

- Incentives to increase scientific engagement, inclusion of the society and reputation building;

- Funding of research and teaching including the necessary developments and upgrades of infrastructures and services;

- Standards like the FAIR principles to ensure collaboration between research and infrastructure, including measures for skilling (data science);

- Public-private partnerships integrate open science in the society and monitor the cooperation between public-law research and the private sector.

It becomes clear, how many challenges have to be picked up to establish a governance model for open Science.

Open science will be one of the issues of the Berlin University Alliance of Free University, Humboldt University, Technical University and Charitè ${ }^{7}$. These institutions will connect to this international development of research and education linked to EU initiatives. The prerequisites for the implementation of open science are new governance structures, for which initial approaches are available. Final solutions, however, do not exist yet. The institutions involved in the joint application of the Berlin University Alliance can significantly contribute to the further development of these approaches and at the same time benefit from international cooperation for their excellence.

By developing a new governance model of open science suitable participation and decision-making structures will be established on the basis of the questions mentioned before. At the same time effective measures for organizational development will be taken up to exploit the potential of open science and to design the cooperation within the Berlin University Alliance. In this way the claim for excellence of the Berlin University Alliance can and will be integrated into the international context.

\footnotetext{
${ }^{5}$ https://github.com/

${ }^{6}$ Knowledge Exchange approach towards Open Scholarship. - Authored by: Based on contributions from the Knowledge Exchange Open Scholarship Advisory Group (see page 10) and edited by Cameron Neylon. - Report dated: August 2017 - elektronischer Zugang: https://repository.jisc.ac.uk/6685/1/KE_APPROACH_TOWARDS_OPEN_ SCHOLARSHIP_AUG_2017.pdf - s. Chapter 4: The economy of open scholarship. - S. 24ff

${ }^{7}$ https://www.universities-berlin.de/en/news/items/20180221-letter-of-intent.html
} 